\title{
Le banc d'orfèvre du prince électeur Auguste de Saxe (1526-1586) au Musée national de la Renaissance
}

\section{Catherine Cardinal}

\section{(2) OpenEdition}

1 Journals

\section{Édition électronique}

URL : http://journals.openedition.org/artefact/527

DOI : 10.4000/artefact.527

ISSN : 2606-9245

\section{Éditeur :}

Association Artefact. Techniques histoire et sciences humaines, Presses universitaires du Midi

\section{Édition imprimée}

Date de publication : 1 octobre 2016

Pagination : 367-370

ISBN : 978-2-7535-5174-9

ISSN : 2273-0753

Référence électronique

Catherine Cardinal, « Le banc d'orfèvre du prince électeur Auguste de Saxe (1526-1586) au Musée national de la Renaissance », Artefact [En ligne], 4 | 2016, mis en ligne le 07 juillet 2017, consulté le 15 septembre 2020. URL : http://journals.openedition.org/artefact/527

\section{(c) (i) (9)}

Artefact, Techniques, histoire et sciences humaines est mise à disposition selon les termes de la Licence Creative Commons Attribution - Pas d'Utilisation Commerciale - Pas de Modification 4.0 International. 


\section{Le banc d'orfèvre du prince électeur Auguste de Saxe (1526-1586) au Musée national de la Renaissance}

Catherine CARDINAL

En 1565, le mécanicien et inventeur Leonhard Danner (1507?-1585) fabriquait, dans son atelier de Nuremberg, une machine-outil servant à tréfiler les fils de métal, commandée par Auguste de Saxe (illustrations 29 et 30, cahier couleur). Après avoir été une œuvre maîtresse de la kunstkammer de l'électeur, le banc à tréfiler passa dans le commerce de l'art puis successivement au musée Carnavalet, au musée de Cluny et, finalement, au musée national de la Renaissance, à Écouen, où il a retrouvé tout son prestige dans une salle qui lui est dédiée ${ }^{1}$. Imposant par son poids de $600 \mathrm{~kg}$ et sa longueur de $4,40 \mathrm{~m}$, il est

\section{Les usages du banc}

Le banc permet, grâce à l'adaptation d'accessoires spéciaux, d'obtenir des fils d'or et d'argent très fins comme des fils en fer de fortes sections. Son mécanisme novateur inclut un dispositif de démultiplication de l'énergie engendrée par le mouvement des artisans; Werner Gunther souligne que «deux hommes le seul parvenu jusqu'à nous pour cette époque. Objet d'apparat par son riche décor de marqueterie et de gravures, il est aussi une étonnante machine dont la conception est révolutionnaire. Ses caractéristiques techniques ont été nouvellement mises en lumière grâce à une recherche menée en partenariat par le musée et l'École nationale d'ingénieurs de Metz. L'étude a abouti à une modélisation en trois dimensions qui le montre en fonctionnement. Cette présentation numérique, à la fois technique et historique, est visible sur un site internet qui lui est consacré et sur une borne multimedia interactive dans le musée ${ }^{2}$.

agissant sur les deux manivelles de concert arrivent à développer, après pertes dans le mécanisme, un effort de traction correspondant à neuf tonnes ${ }^{3}$ ». Des outils amovibles et de nombreuses filières de divers profils complètent le système principal (illustration 31, cahier couleur). La présentation virtuelle $\mathrm{du}$ 
banc permet de comprendre ses divers modes de fonctionnement et d'observer notamment que le travail peut se faire en continu de part et d'autre de la crémaillère. « Cette conception de la machine consistant à permettre d'éviter un retour à vide de la crémaillère est représentative d'une vision productiviste tout à fait moderne » ajoute W. Gunther" .

\section{L'inventeur du banc et sa destination}

Leonhard Danner est un mécanicien réputé, bourgeois de Nuremberg, travaillant au service de sa ville et de divers commanditaires. Dès les années 1550 et jusqu'à sa mort, il livre de nombreuses commandes à Auguste de Saxe qui apprécie ses inventions dans le domaine de l'outillage et de l'armement ${ }^{5}$; comme le remarque Michèle Bimbenet-Privat, le banc est « le résultat de la relation fructueuse d'un commanditaire exceptionnel, un prince passionné de mécanique, et d'un formidable inventeur ${ }^{6} »$. La machine est installée dans une des sept salles, la kunstkammer, aménagée sous les toits du château de Dresde. Le premier inventaire de ces "salles d'art», daté de 1587, mentionne plus de 7000 outils pour menuisiers, serruriers, armuriers, orfèvres et 400 horloges, automates et instruments de géodésie, d'optique, d'as- tronomie, représentant les trois-quarts des collections ${ }^{7}$. Auguste manifeste un véritable intérêt envers les techniques, attirant à la cour de Dresde des artisans et des ingénieurs réputés, pouvant perfectionner les métiers. Ils sont chargés de travailler avec les outils collectés par le prince, répartis dans des ateliers spécialisés comme celui dédié au tournage où se trouvait un tour également acquis auprès de Danner en 1561. Auguste luimême s'adonne en leur compagnie à des travaux de menuiserie et d'orfèvrerie. Sa kunstkammer répond donc avant tout à ses goûts personnels plutôt qu'à une fonction de représentation officielle ou à une fonction décorative; elle n'est pas seulement une collection d'outils ingénieux et d'instruments sophistiqués mais aussi un lieu de production.

\section{Le décor du banc}

À l'instar de nombreux objets techniques de la Renaissance, le banc d'orfèvre est également une œuvre d'art, représentative de la dextérité des marqueteurs allemands $\mathrm{du} \mathrm{xvI}^{\mathrm{e}}$ siècle. Leonhard Danner a collaboré avec un maître-menuisier, resté anonyme, dont

l'on note le monogramme $\mathrm{AM}$, répété trois fois sur le banc, ainsi que son autoportrait le représentant au travail dans son atelier (illustration 32, cahier couleur). Le programme iconographique se révèle en lien avec la personnalité $\mathrm{d}^{\prime}$ Auguste de Saxe, prince humaniste et 
partisan de la Réforme. Un tournoi ayant des accents de parodie donne la victoire au chevalier affilié à Auguste contre le représentant du pape. Une frise met en opposition des hommes drapés à l'antique, occupés à saccager une ville, et des hommes sauvages pleins de dignité, couronnés de laurier ou chevauchant majestueusement des animaux féroces.

" L'iconographie du banc combine ainsi satire des catholiques en contexte de guerres de religion et réflexion sur la place de l'homme dans la nature. Tous ces éléments, joints aux armoiries, concourent à célébrer Auguste, champion de la cause luthérienne légitimé par Dieu et par l'Histoire ", comme le remarque Stéphanie Deprouw-Augustin ${ }^{8}$. La présence de ses armoiries sur un petit côté atteste l'importance qu'il a donnée à sa commande, suivant sans doute de près la conception des frises narratives dont les modèles pourraient avoir été fournis par le peintre et graveur suisse Jost Amman, établi à Nuremberg depuis 1560 environ (illustration 33, cahier couleur).

La marqueterie n'est pas la seule technique utilisée dans la décoration du banc ${ }^{9}$. Les éléments métalliques, comme les outils en fer attenant, sont soigneusement gravés de saynètes, d'allégories, de rinceaux peuplés dans la manière des petits maîtres de la Renaissance. Observons que de tels décors caractérisent aussi, par exemple, les armes et les horloges de table fabriquées à la même époque.

La pièce, fastueuse par son décor et ingénieuse par ses capacités techniques, est bien représentative des ouvrages commandés par les princes du temps comme les sphères et les horloges à complications astronomiques ${ }^{10}$. Grâce à la restauration effectuée en 2010 et au projet numérique dont elle a bénéficié un an plus tard, le public peut pleinement en mesurer l'intérêt ${ }^{11}$. Des présentations virtuelles de ce genre seraient souvent souhaitables pour comprendre le mécanisme et la fonction d'objets exposés dans les musées qui, faute d'explications et de démonstrations, apparaissent tels des témoins muets de l'avancement des techniques.

\section{Notes}

1. Le banc d'orfèvre, vendu par l'État de Saxe dans le deuxième tiers du xix ${ }^{e}$ siècle, fut acquis par la ville de Paris, présenté au musée Carnavalet à une date indéterminée puis conservé au musée de Cluny dès 1886. En 1981, il prend place au Musée national de la Renaissance, nouvellement ouvert dans le château d'Écouen.

2. [http//www.musée-renaissance.fr/files/complement/bancdorfevre/index2.html]. La présentation compte onze séquences permettant notamment de comprendre le fonctionnement du banc (travail du fil précieux, travail du gros fil, laminage des barres de fer) et de découvrir les détails de la marqueterie.

3. Werner GunTHER, "Le banc à tréfiler; une expérience de modélisation ", in Michèle BimbenETPrivat (dir.), Le banc d'orfeure de l'électeur de Saxe, Paris, Réunion des musées nationaux, 2012, p. 60.

4. Ibid., p. 61.

5. Ibid., se référer à l'article de Bertrand BergBaUer, " Lenohard Danner, concepteur du banc », in M. Bimbenet-Privat (dir.), Le banc d'orfevre, op. cit., p. 47-53.

6. M. Bimbenet-Privat, " Les bancs à tirer et la mécanisation dans les ateliers d'orfèvres ", in M. Bimbenet-Privat (dir.), Le banc d'orfevre, op. cit., p. 67.

7. Martina MinNing, " Les outils de la Kunstkammer de Dresde et leur histoire », in M. Bimbenet-Privat (dir.), Le banc d'orfevore, op. cit., p. 31-45.

8. Stéphanie Deprouw-Augustin, « Le décor du banc d'orfèvre : marqueterie, gravure et dorure ", in M. Bimbenet-Privat (dir.), Le banc d'orfêre, op. cit., p. 86.

9. Ibid., p. 84 .

10. Se référer par exemple au catalogue d'exposition: Catherine Cardinal et Dominique Vingtain 
(dir.), Le temps et sa mesure du Moyen Âge à la Renaissance. Trésors d'horlogerie, Avignon, Palais des papes, 1998.

11. L'auteur remercie vivement de leur accueil et de leur aide Monsieur Thierry Crépin-Leblond, directeur du Musée national de la Renaissance et Monsieur Guillaume Fonkenell, conservateur. 